\title{
O enigma do desejo: uma interface entre psicanálise e literatura
}

\author{
The enigma of desire: an interface between psychoanalysis and literature
}

El enigma del deseo: una interfaz entre psicoanálisis y literatura

Recebido: $14 / 05 / 2020$

Aprovado: 09/12 /2020

Publicado: 18/04/2021

\author{
Rita de Cássia Ramos ${ }^{1}$ \\ Paulo Rodrigo Unzer Falcade ${ }^{2}$ \\ Araceli Albino ${ }^{3}$
}

Esta é uma revisão narrativa realizada no primeiro semestre de 2020, com o objetivo de descrever a noção de desejo fundamentada na teoria lacaniana e freudiana e ilustrá-la com um texto literário portador de perspectiva análoga. Este trabalho apresenta os seguintes tópicos: $o$ enigma da noção de desejo, delimitação teórica, definição psicanalítica, laço entre literatura e psicanálise e ilustração literária. A partir desse percurso, verificou-se que a definição psicanalítica do desejo, que difere da proveniente do senso comum e da filosófica, encontra correspondência em um poema do escritor simbolista Camilo Pessanha.

Descritores: Libido; Psicanálise; Teoria freudiana; Literatura, Poesia.

This is a narrative review carried out in the first half of 2020. It aims to describe the notion of desire based on Lacanian and Freudian theory, and with the symbolic aid of a literary text with a similar perspective. This work presents the following topics: the enigma of the notion of desire, theoretical delimitation, psychoanalytical definition, link between literature and psychoanalysis and literary illustration. From this path, it was found that the psychoanalytic definition of desire, which differs from that of common and philosophical senses, finds correspondence in a poem by the Brazilian symbolist writer Camilo Pessanha.

Descriptors: Libido; Psychoanalysis; Freudian theory; Literature; Poetry.

Esta es una revisión narrativa realizada en el primer semestre de 2020, cuyo objetivo es describir la noción de deseo fundamentada en la teoría lacaniana y freudiana e ilustrarla con un texto literario de perspectiva análoga. Este trabajo presenta los siguientes temas: el enigma de la noción de deseo, delimitación teórica, definición psicoanalítica, vínculo entre literatura y psicoanálisis e ilustración literaria. En el artículo, se encontró que la definición psicoanalítica del deseo, que difiere de la proveniente del sentido común y de la filosófica, encuentra correspondencia en un poema del escritor simbolista Camilo Pessanha.

Descriptores: Libido; Psicoanálisis; Teoría freudiana; Literatura; Poesía.

1. Bacharel e Licenciada em Letras Português/Alemão. Psicanalista. Especialista em Ciências Humanas. Mestre em Língua Portuguesa. Doutora em Literatura Portuguesa. Professora de Literatura do Colégio Objetivo, São Paulo, SP, Brasil. ORCID: 0000-0002-9749-3993 E-mail: profa.cassiapsi@gmail.com

2. Psicólogo. Mestre e Doutor em Psicologia Social. Professor do NPP, São Paulo, SP, Brasil. ORCID:0000-0002-2980-5430 E-mail: paulounzer@gmail.com

3. Psicóloga. Psicanalista. Especialista em Psicanálise e Linguagem. Especialista em Psicopatologia Psicanalítica e Contemporânea. Especialista em Psicoterapia. Doutora em Psicologia. Coordenadora do NPP, São Paulo, SP, Brasil. ORCID: 0000-0002-1391-8553 E-mail: araceli.albino@uol.com.br 


\section{INTRODUÇÃO}

A

psicanálise desde o começo mostrou sua eficácia tanto no tratamento de grande número de psicopatologias, como na resolução de conflitos familiares, de casais e mesmo

profissionais ${ }^{1}$. A frequência com que a psicanálise é solicitada para a compreensão de acontecimentos sociais atesta sua importância e a extensão de sua aplicabilidade.

Destarte, as noções da psicanálise são referidas dentro e fora do campo analítico, mas nem sempre com a devida compreensão, como ocorre com a noção de desejo. 0 fato de o termo ser muito popular e polissêmico contribui para sua imprecisão. No dicionário de sinônimos ${ }^{2}$, encontram-se oito sentidos atribuídos a "desejo". São eles: "querer", "ambição", "apetite”, "atração física", "propósito", "capricho", "arrebatamento", "vontade própria", e, para esse conjunto de sentidos, há cerca de mais de setenta sinônimos.

A noção de desejo também pode se confundir com a advinda do campo filosófico. Ao longo da história da filosofia, diversos pensadores apresentaram diferentes perspectivas para a compreensão da questão do desejo. No entanto, desde que a psicanálise articulou a noção de desejo do ponto de vista do inconsciente, a perspectiva psicanalítica tornou-se referência constante, para ser seguida ou contraposta inclusive pela própria filosofia.

No domínio psicanalítico, o desejo ocupa posição central na teoria freudiana e lacaniana. A novidade desta pesquisa é apresentá-la em interface com um texto literário que aqui se considera como portador de visão correspondente. Assim, este estudo tem como objetivo descrever a noção de desejo fundamentada na teoria lacaniana e freudiana e ilustrá-la com um texto literário portador de perspectiva análoga.

\section{MÉTODO}

Esta é uma revisão narrativa que utilizou obras que tratam da noção do desejo conforme a linha teórica lacaniana e freudiana em contraste com um texto literário. A escolha do poema analisado, por sua vez, respeitou o seguinte critério: ter uma visão corresponde à da psicanalítica.

Esse estudo foi realizado no primeiro semestre de 2020, está associado à pesquisa de aspectos do conceito de fantasia, conforme abordagem freudiana e lacaniana, feita pelo grupo de estudos lacanianos da instituição: Núcleo de Pesquisas Psicanalíticas (NPP), SP, Brasil.

\section{RESULTADOS}

Esta revisão teve como base 17 referências e se dividiu nas seguintes áreas temáticas: $O$ enigma da noção de desejo, Delimitação teórica, Definição psicanalítica, Laço entre psicanálise e literatura, e Ilustração literária.

\section{DISCUSSÃO}

\section{O enigma da noção de desejo}

0 mistério acerca do que é o desejo atravessa o campo da Filosofia ocidental já se encontrava presente no "Banquete de Platão"3 e continua sendo uma questão atual.

A noção de desejo proveniente da psicanálise tornou-se um elemento central na discussão desse fenômeno no próprio âmbito filosófico, seja na forma de contraponto ${ }^{4}$, seja no reconhecimento da noção filosófica inserida na linhagem freudiana ${ }^{5}$.

Na literatura, o tema do desejo é de longa data. Sua incógnita está presente nos textos de poetas líricos e trágicos da Antiguidade Clássica. Discute-se até uma possível origem ainda mais remota: a de que o $\theta v \mu o \varsigma$ (thymós) dos poemas épicos de Homero possa ser considerado como uma manifestação embrionária da noção de desejo ${ }^{6}$. No diálogo profícuo entre Literatura e Psicanálise, em perspectiva lacaniana encontrou-se na peça teatral Antígona, de Sófocles, um exemplo perfeito para ilustrar o conceito de desejo ${ }^{7}$. 
0 enigma do desejo, portanto, foi tratado pela Literatura e pela Filosofia, antes da Psicanálise. No entanto, hoje é a Psicanálise a referência maior para a elucidação de seu mistério. Esse destaque deve-se especialmente ao fato de a problemática do desejo ter sido reconhecida como central na direção lacaniana que elevou a noção freudiana a nível conceitual.

Embora numa proposta lacaniana o enigma do desejo já esteja decifrado nem sempre é compreendido. Essa dificuldade decorre do fato de que o campo do saber psicanalítico é o do inconsciente e, sendo assim, não é meramente pela via intelectualista que se apreende uma noção desse domínio, mas sim pela via legítima e eficaz de acesso aos saberes do inconsciente, que é a da experiência analítica.

Se nada substitui a experiência analítica como via de acesso ao saber sobre processos psíquicos inconscientes, considera-se, todavia, neste trabalho, que o encontro de um texto literário que tenha correspondência à noção de desejo pode ser produtivo.

\section{Delimitação teórica}

A noção do desejo diz respeito a um campo da psicanálise, bem delimitado como o do inconsciente.

0 inconsciente é a base de toda a vida psíquica, a realidade essencial do psiquismo. Pode ser estudado sob diferentes pontos de vista: descritivo, sistemático, dinâmico, econômico e ético ${ }^{8}$. Com destaque ao aspecto ético, Lacan afirma que o estatuto do inconsciente não é ôntico e sim ético ${ }^{9}$.

Do ponto de vista descritivo, o inconsciente é apreendido a partir de manifestações que surgem e ultrapassam o saber consciente (atos falhos, esquecimentos, sonhos, ideias repentinas, criações improvisadas de poemas, de conceitos, sintomas) ${ }^{8,9}$.

Do ponto de vista sistemático, pressupõe-se a divisão do psiquismo em duas instâncias: o sistema inconsciente, em que se encontram (imagens acústicas, visuais ou tácteis), "chamadas representações de coisa", e o consciente (sistema formado também pelo pré-consciente), que contém as "representações de palavra". O recalcamento é a barreira que separa os dois sistemas, mas não é infalível. 0 sistema inconsciente é regido pelo princípio de prazer-desprazer e o consciente pelo princípio de realidade ${ }^{8,9}$.

0 ponto de vista dinâmico acerca do inconsciente, atém-se, em especial, à luta entre uma força que impulsiona e a resistência operada pelo recalcamento. As "representações de coisa" do inconsciente são, a partir desse prisma, denominadas de "representantes recalcados" e o que conseguiu passar pela barreira do recalcamento são os produtos deturpados de tais representantes. A esses derivados dissimulados, dá-se o nome de "retorno do recalcado", "produtos do recalcado", ou ainda, "produtos do inconsciente"8,9.

Do ponto de vista econômico, trata a fonte de excitação como "representante das pulsões" e as produções finais do inconsciente como comportamentos afetivos e escolhas amorosas espontâneas escoradas em fantasias inconscientes. A definição do ponto de vista ético será dada no próximo item ${ }^{8,9}$.

No decorrer da história da psicanálise, na perspectiva freudiana e lacaniana houve muitas mudanças em relação ao conjunto de postulados teóricos, acompanhando as transformações que se deram em todas as áreas do conhecimento, considerado científico ou humanístico ${ }^{10}$.

De uma forma esquemática, pode-se dividir a história da psicanálise em ortodoxa, clássica e contemporânea. Cada uma dessas etapas apresenta alterações importantes em seus paradigmas. Contudo, embora tenha havido profundas transformações nas concepções teóricas, a psicanálise contemporânea continua "conservando os ideais e os princípios básicos freudianos" 10 dentre eles, a noção do inconsciente e das pulsões.

A perspectiva lacaniana, que retoma o olhar freudiano, avançou no conceito de desejo, trazendo contribuições da Linguística, como a concepção de significante e de um inconsciente organizado como linguagem; e da Antropologia, da qual ele deduziu a noção do simbólico, utilizado na tópica SIR (simbólico, imaginário, real), bem como sua releitura do complexo de 
Édipo e da interdição do incesto. A noção de desejo formulada pela psicanálise resulta dessa visão multifacetada ${ }^{10}$.

\section{Definição psicanalítica}

O campo da psicanálise é o do inconsciente e a noção de desejo está circunscrita a ele. Na perspectiva psicanalítica, portanto, o que importa quanto à noção de desejo não diz respeito ao consciente, nem à vontade, mas relativo a processos psíquicos inconscientes.

A Psicanálise deixa claro que a noção de desejo a que ela se refere diz respeito a "um desejo desnaturalizado e lançado na ordem simbólica", que "só pode ser pensado na sua relação com o desejo do outro e aquilo para o qual ele aponta não é o objeto empiricamente considerado, mas uma falta". Articulado a essa falta estrutural, o desejo "desliza como que numa série interminável, numa satisfação sempre adiada e nunca atingida"11.

Considerando-se a definição de inconsciente do ponto de vista ético, "o desejo é o inconsciente considerado do ponto de vista da sexualidade, isto é, do ponto de vista do prazer sexual"8.

Segundo o estatuto ético do inconsciente,-“o desejo é uma pulsão da qual não se tem consciência, que teria por objetivo ideal o prazer absoluto em uma relação incestuosa"8. Esse incesto, todavia, cabe frisar, não diz respeito às práticas incestuosas patológicas e vedadas por lei que possam ser cometidas. 0 incesto a que a psicanálise se refere é mítico e é ansiado, de forma inconsciente, como o bem mais desejado entre todos, consistindo naquilo que orienta a vida de cada ser humano e que sobre ela delibera.

$\mathrm{Na}$ teoria psicanalítica, os lapsos que se comete, bem como os sonhos, têm significado oculto, que diz respeito ao fato de serem substitutos de um ato ideal, que, apesar disto, não ocorreu. Essa significação velada, nos atos aparentemente sem sentido por nós perpetrados, é sempre sexual.

Para a psicanálise, os humanos não são seres instintivos, mas pulsionais, movidos por tendências originadas em uma zona erógena corporal definida, que pode ser os olhos, a voz, a pele, a boca, o ânus e outras, cuja excitação é continuada. Essas pulsões, que são múltiplas, se localizam no nosso inconsciente e ali permanecem desde muito cedo até a morte.

As pulsões seguem uma trajetória de busca de um ideal impossível, que consiste numa satisfação sexual absoluta. Durante esse percurso, elas se deparam com o recalcamento e, no caso de ultrapassarem essa barreira, exprimem-se como atos substitutivos do incesto ideal, que é a satisfação sexual plena, impossível de se realizar.

A pulsão sexual na proposta freudiana é composta por quatro elementos: a fonte (zona erógena), de onde a pulsão se origina; a força, que movimenta a pulsão; o objetivo, que a atrai; o objeto (coisa, ou pessoa, sendo sempre objeto fantasiado), que é o meio pelo qual a pulsão busca atingir seu objetivo ideal, isto é, "o prazer perfeito de uma ação perfeita, de uma perfeita união entre dois sexos, cuja imagem mítica e universal seria o incesto" 8,12 .

A psicanálise pressupõe que toda conduta, caso tenha uma tendência originada numa zona erógena e seja apoiada numa fantasia que resulte num prazer sexual limitado, é sexual. 0 prazer obtido pela sexualidade humana, considerada no mais amplo sentido, é diferente do proveniente da mera satisfação de uma necessidade fisiológica.

Nos componentes elencados e abordados, tem-se que: o objetivo ideal do desejo é o incesto; o objeto do desejo é a fantasia do corpo desejante do outro; o desejo nasce de uma zona erógena definida, de excitação constante; o prazer proporcionado pelo desejo é parcial, qualificado de sexual; e um exemplo do Outro do desejo é a mãe desejante e desejada ${ }^{8}$. No desejo, o apego ao outro desejado corresponde "ao apego a um objeto fantasiado, polarizado em torno de uma zona erógena situada no corpo do outro"8.

0 desejo difere tanto da necessidade quanto do amor. A necessidade diz respeito a uma tendência orgânica, que parte de uma zona orgânica, com vistas a autoconservação e o prazer obtido é o da saciação, como no da mãe alimentadora. 0 amor, por sua vez, segue a tendência 
da fusão com o amado. 0 objeto imaginário é o semelhante idealizado e o prazer sexual é sublimado e um exemplo do Outro do amor é a mãe ideal ${ }^{8}$.

Em si, o desejo deseja desejar, mas isso seria justamente o que haveria de mais sublime do desejar na fala lacaniana, porque há um risco de o desejo ser capturado por um sintoma, que é o que ocorre nas neuroses, e há o risco do desejo ser capturado por um fetiche, como é o caso da perversão. Então, o desejo não está nem no campo do sintoma, nem no campo do fetiche, o desejo, de certa forma, seria aquilo que resiste ao anseio pelo gozar, sem ao mesmo tempo neutralizar esse desejo de gozo, então, no fundo, o desejo é aquilo que mantém a vivacidade humana.

\section{Laço entre psicanálise e literatura}

Há diferenças entre o discurso psicanalítico e o discurso literário, mas também há pontos de contato. A partir da proximidade entre ambos, a crítica literária utiliza-se de pressupostos psicanalíticos para interpretar uma determinada obra e teóricos da psicanálise, por sua vez, desde seu início, têm interesse pela linguagem enigmática dos textos produzidos por escritores criativos por eles manifestarem conteúdos inconscientes.

Os escritores devem ser respeitados, uma vez que eles podem ensinar muito sobre o saber inconsciente. De acordo com Mango (2014 p.18) ${ }^{13}$, "Freud teve a coragem de introduzir no saber científico a figura do Dichter, do poeta, severamente apartado pela academia de sua época"13, de modo que os textos elaborados por escritores criativos propiciam um acesso inigualável à realidade psíquica, reconhecendo-se aqui a importante relação da psicanálise à literatura.

A ocupação da psiquiatria clássica era a de descrever enfermidades e, no olhar e prática freudiana, se vai além do limite da ciência da época, uma vez que o interesse estava voltado para a compreensão do psiquismo como uma totalidade, não se recusando, pelo contrário, insistindo na pesquisa sobre os processos inconscientes. A medicina positivista ou a biologia não se ocupa do inconsciente, mas sim a poesia e suas ambivalências, desvios, disfarces, ocultamentos e revelações ${ }^{14}$,

Por caminhos diferentes e procedimentos próprios, psicanálise e literatura acabam por tocar na complexidade da interioridade humana. A busca por um diálogo entre esses dois diferentes campos, revela-se produtiva para a elucidação de enigmas, na tentativa de compreensão da noção de desejo.

\section{Ilustração literária}

No poema de Camilo Pessanha ${ }^{15}$, tido como o mais original escritor do Simbolismo português, verifica-se um diálogo entre Psicanálise e Literatura, buscando-se amadurecimento reflexivo sobre a noção do enigma do desejo. Este poema oferece, tanto no plano do conteúdo como no da forma, que são indissociáveis, uma compreensão da problemática do desejo.

0 texto aqui interpretado pertence ao Simbolismo, movimento que surgiu na França em fins do século XIX, e de lá se difundiu internacionalmente, abrangendo diversos ramos artísticos, principalmente a poesia. Porém, "nem toda literatura que usa o símbolo é simbolista, mas a poesia universal é toda ela na essência simbólica". A poesia simbolista é aquela que buscou "instalar um credo estético baseado no subjetivo, no pessoal, na sugestão e no vago, no misterioso e ilógico, na expressão indireta e simbólica"15. 0 poema apresentado traz estrofes e uma toda pontilhada: 
Se andava no jardim,

Que cheiro de jasmim!

Tão branca do luar!

(...)

Eis tenho-a junto a mim.

Vencida, é minha, enfim,

Após tanto a sonhar...

Porque entristeço assim?

Não era ela, mas sim

(O que eu quis abraçar)

A hora do jardim...

O aroma do jasmim...

A onda do luar...

(Pessanha, p. 28) ${ }^{16}$

Numa exploração inicial, verifica-se que o poema é composto por cinco estrofes, cada uma delas com três versos hexassílabos (seis sílabas métricas) e seguindo a um mesmo esquema de rimas (AAB). A função de um texto literário é o de provocar prazer estético e esse poema tem êxito nisso, ao usar essa forma poética que cativa o leitor pela leveza do ritmo de seu verso curto.

Na primeira estrofe, pode-se notar a presença de um eu que expressa seu estado de espírito. Do ponto de vista da criação poética, esse "eu" é ficcional, elemento usado no processo artístico e que não se confunde com a pessoa do poeta.

Nela, o eu lírico desse poema afirma seu êxtase diante de uma figura feminina, num momento em que ele andava por um jardim perfumado e enluarado e ali a avista. A mulher, em perfeita consonância com a poética simbolista, segundo a qual a sugestão deve prevalecer sobre a descrição do objeto, é apontada de forma muito discreta, apenas pelo adjetivo "branca", termo que diz menos sobre a coloração da pele feminina do que sobre a brancura do luar que ilumina o jardim. Nessa estrofe, o sujeito poético revela-se tomado por um desejo e, sendo ele o desejante, a mulher passa a ocupar a posição de objeto de seu desejo.

No poema original, a próxima estrofe é construída apenas por meio de pontuação sugestiva, e por meio desse recurso gráfico, evidencia-se todo o esforço do eu lírico para a conquista de seu objeto. As linhas pontilhadas expressam, assim, muito mais do que se estivessem completas por palavras.

Na estrofe seguinte, o eu lírico coloca em primeiro plano o momento da efetivação do ato de conquista. As palavras com que ele se refere à mulher que fora conquistada evidenciam sua posição de objeto passivo. São eles: “ $a$ ", pronome pessoal usado na forma oblíqua, forma própria da função sintática de objeto; "vencida", particípio passado e "minha", pronome possessivo. $\mathrm{O}$ eu poético é apresentado nitidamente no lugar de agente do apoderamento amoroso.

Além disso, há, nessa estrofe, a contraposição entre dois termos: "vencida" e "sonhar", que remetem à separação entre dois planos: o do mundo concreto e o da fantasia. É digno de nota a força com que, no poema, a presença da mulher no universo onírico ou dos devaneios do eu poético é revestida, como sugere o advérbio de intensidade "tanto". Também merece relevo a marcação no poema de uma dicotomia temporal: um tempo do desejo irrealizado e um tempo de sua realização, referido pelo advérbio "após".

$\mathrm{Na}$ quarta estrofe, ocorre a ruptura: o sujeito poético coloca em primeiro plano uma inesperada tristeza, resultado de um movimento deceptivo, que somente é percebido por ele no momento em que a conquista foi consumada. No momento posterior à conquista, marcado pelo termo "após", o eu lírico, em vez de ficar feliz por ter alcançado a posse do objeto de seu desejo, frustra-se, decepciona-se. 0 que parece incompreensível. Sua tristeza, conforme afirma, 
denuncia para ele próprio algo de que não tinha consciência: não era aquela mulher vista por ele o objeto de seu desejo. Há o desencontro entre o ideal e o real.

0 verbo "abraçar" evidencia que foi no momento dessa ação concreta que o eu lírico se decepcionou, pois o suposto objeto de seu desejo, ao ser envolvido por seus braços, não lhe ofereceu a experiência ansiada: a sensação de completude, que estava delineada na dimensão inconsciente, sob a forma de uma fantasia.

Aqui fica destacada a vulnerabilidade que habita o "eu" em sua relação com o objeto de seu desejo, fato que a Psicanálise freudiana e lacaniana evidencia ao tratar da noção de desejo. O sujeito, que esperava ter uma vivência de completude, decepciona-se em razão de o objeto de desejo ser intrinsecamente um objeto deslizante, se articulado a uma fantasia inconsciente.

No poema, o eu lírico não questiona o que lhe provoca tristeza. Na experiência analítica, caso essa queixa fosse apresentada, ela teria um recorte subjetivo e os motivos desse sentimento seriam pelo próprio sujeito questionados, haveria uma implicação subjetiva sobre esse sentir. No poema, no entanto, o eu poético parece intuir a impossibilidade do encontro entre sujeito e objeto, ele não afirma claramente, mas parece ter um saber sobre a impossibilidade da concretização da fantasia que o move inconscientemente para um objeto incapaz de completar sua falta estrutural.

$\mathrm{Na}$ estrofe final, num movimento reflexivo, essa ideia de que é impossível satisfazer o desejo é sugerida a partir de expressões sugerem coisas inatingíveis por meio das quais ele tenta recobrir a fluidez do campo do objeto: "hora do jardim", "aroma de jasmim", "onda de luar". Assim, num movimento circular que pressupõe o movimento contínuo do próprio desejo, ele retoma o momento anterior à concretização do seu desejo.

A forma negativa de Pessanha (1989) ${ }^{16}$ ao se referir ao desejo, nesse poema, é um elemento confirmado pela crítica literária:

Em toda a obra de Pessanha, parece-nos haver apenas um ou outro poema em que o desejo nos aparece em seu momento afirmativo, positivo (...). Nos demais, de que é um bom exemplo o que começa pelo verso "Se andava no jardim", temos sempre o reverso da medalha, o momento em que se patenteia a inconsistência do objeto do desejo e, portanto, a impossibilidade de realização amorosa ${ }^{17}$.

0 crítico literário ${ }^{17}$ afirma que não se trata apenas desse poema, mas com raras exceções, toda a obra de Pessanha é marcada pela negatividade do desejo. Essa negatividade do desejo também é apontada pela Psicanálise, em especial, a partir do ensino de lacaniano.

Uma lição maior que fica, a partir dessa associação entre a teoria da psicanálise e a experiência produzida pela leitura do poema, é que, embora o objeto do desejo seja inconsistente, o desejo, em si, é indestrutível, como afirma a Psicanálise, pois remete ao ideal do incesto mítico. No poema, essa indestrutibilidade do desejo fica evidente no uso do verbo "abraçar", ação desejada pelo "eu" desde o instante inicial, em que o meio de realização do desejo lhe era figurado ilusoriamente como uma mulher avistada num jardim de atmosfera encantadora.

Nessa sugestiva pontuação simbolista: “(O que eu quis abraçar)”, os parênteses adquirem uma significação que colabora para a coerência final desse texto poético. Por sua forma, os parênteses sugerem o próprio ato de abraçar, ação esta que, somente no âmbito da fantasia, poderia reter seu objeto do desejo, que, do ponto de vista da Psicanálise, alude à fantasia do corpo desejante do Outro. Assim, os parênteses aludem ao paradoxo do desejo: embora impossível, a relação de total completude entre sujeito e objeto é sempre desejada.

\section{CONCLUSÃO}

Nesse trabalho, foram vistos alguns aspectos da questão do desejo, considerando a perspectiva psicanalítica em interface com um texto literário, reconhecendo-se o papel supremo do desejo para a manutenção da vivacidade humana, na medida que o desejar se contrapõe ao movimento mortífero do gozar. 
A leitura e interpretação de um texto literário leva a reflexão sobre a condição humana, de seres incompletos, perenemente insatisfeitos, pois o desejo, estruturalmente, diz respeito a um prazer sexual limitado, que traz o sentimento sempre decepcionante quando comparado ao ideal de completude inscrito no inconsciente, desde a mais tenra idade.

Esses aspectos não recobrem toda a problemática do desejo em Psicanálise, contudo a descreve, apresentando sua especificidade e capacidade de elucidar aspectos enigmáticos de um conceito de importância crucial na teoria e prática psicanalíticas.

Como limitação esta revisão não pretendeu esgotar o "enigma do desejo", por vários aspectos, até mesmo pela diversidade de áreas científicas que se interessam pelo tema. Por sua vez, esse diálogo entre Psicanálise e Literatura, inaugurado no olhar freudiano e retomado por diversos estudiosos ao longo da história psicanalítica, aqui também se revelou produtivo e pode ser útil para pesquisas acerca conceitos psicanalíticos.

\section{REFERÊNCIAS}

1. Nasio JD. Sim, a psicanálise cura! Rio de janeiro: Zahar; 2019. 112p.

2. Dicionário de sinônimos online [Internet]. 2011-2021 [citado em 16 ago 2020]. Disponível em: https://www.sinonimos.com.br/

3. Platão. $O$ banquete [Internet]. Domínio Público, 2001 [citado em 16 ago 2020]. Disponível em http://www.dominiopublico.gov.br/download/texto/cv000048.pdf

4. Furlan R. Desejo, sentimento e relação com o outro na filosofia de vida de Renaud Barbaras. Kriterion [Internet]. 2019 [citado em 09 mar 2021]; 60(142):203-23. Disponível em: https://www.scielo.br/pdf/kr/v60n142/0100-512X-kr-60-142-0203.pdf

5. Viana D. Afeto-emotividade em Simondon e o conceito de desejo. Kriterion [Internet]. 2019 [citado em 09 mar 2021]; 60(144):537-61. Disponível em: https://www.scielo.br/pdf/kr/v60n144/0100-512X-kr-60-144-0537.pdf

6. Rocha Z. O desejo na Grécia Arcaica. Rev Latinoam Psicopatol Fundam. [Internet]. 1999 [citado em 09 mar 2021]; 2(4):94-122. Disponível em:

https://www.scielo.br/pdf/rlpf/v2n4/1415-4714-rlpf-2-4-0094.pdf

7. Lacan J. 0 seminário, livro 7: a ética da psicanálise. Rio de Janeiro: Zahar; 1988. 388p.

8. Nasio JD. 0 prazer de ler Freud. Rio de Janeiro: Zahar; 1999. 113p.

9. Lacan J. 0 seminário, livro 6: o desejo e sua interpretação. Rio de Janeiro: Zahar; 2016. 562p.

10. Zimerman DE. Fundamentos psicanalíticos: teoria, técnica e clínica. Porto Alegre: Artmed; 1999. 910p.

11. Garcia-Roza LA. Freud e o inconsciente. Rio de Janeiro: Jorge Zahar Ed.; 2008. 240p.

12. Freud S. As pulsões e seus destinos. In: Freud S. A interpretação dos sonhos (1900). Rio de Janeiro: Imago; 1996. (Edição Standard Brasileira das Obras Completas de Sigmund Freud; 4). p. 123-44.

13. Pontalis JB, Mango EG. Freud com os escritores. São Paulo: Três estrelas; 2009. 304p.

14. Rosenbaum Y. Literatura e psicanálise: reflexões. Fronteira Z [Internet]. 2012 [citado em 16 ago 2020]; 9:225-34. Disponível em: https://revistas.pucsp.br/index.php/fronteiraz/article/view/13039/9539

15. Simbolismo. In: Enciclopédia Itaú Cultural de Arte e Cultura Brasileiras [Internet]. São Paulo: Itaú Cultural; 2020 [citado em 17 ago 2020]. Disponível em: http://enciclopedia.itaucultural.org.br/termo12154/simbolismo

16. Pessanha C. Clepsidra. São Paulo: Núcleo; 1989. 40p.

17. Franchetti P. Nostalgia, exílio e melancolia: leituras de Camilo Pessanha. São Paulo: Edusp; 2001. 168p. 
Editora Associada: Fernanda Carolina Camargo

\section{CONTRIBUIÇÕES}

Rita de Cássia Ramos contribuiu no desenho do estudo, análise de dados, redação e revisão. Paulo Rodrigo Unzer Falcade participou na orientação e revisão. Araceli Albino atuou na revisão.

\section{Como citar este artigo (Vancouver)}

Ramos RC, Falcade PRU, Albino A. 0 enigma do desejo: uma interface entre psicanálise e literatura. REFACS [Internet]. 2021 [citado em inserir dia, mês e ano de acesso]; 9(2):463-71. Disponível em: inserir link de acesso. DOI: inserir link do DOI

\section{Como citar este artigo (ABNT)}

RAMOS, R. de C.; FALCADE, P. R. U.; ALBINO, A. 0 enigma do desejo: uma interface entre psicanálise e literatura. REFACS, Uberaba, MG, v. 9, n. 2, p. 463-71, 2021. DOI: inserir link do DOI. Disponível em: inserir link de acesso. Acesso em: inserir dia, mês e ano de acesso.

\section{Como citar este artigo (APA)}

Ramos, R.C., Falcade, P.R., \& Albino, A. (2021). 0 enigma do desejo: uma interface entre psicanálise e literatura. REFACS, 9(2), 463-71. Recuperado em inserir dia, mês e ano de acesso de inserir link de acesso. DOI: inserir link do DOI. 